\title{
A retrospective study of behavioural transitions in bicycle use of commuters in Dar-es-Salaam
}

\author{
A. Nkurunziza \& M. F. A. M. van Maarseveen \\ Department of Urban and Regional Planning and \\ Geo-information Management, University of Twente, The Netherlands
}

\begin{abstract}
Travel behaviour literature focuses on factors that influence individual travel behaviour, whether socio-demographic, related to urban form and land use or to attributes of available transport modes. Less attention is given to investigating changes in travel behaviour and a possible relation with events or stages in the life of individuals. This paper examines transitions in cycling behaviour of daily commuters in Dar-es-Salaam, Tanzania. The study adopts the stages of change model to profile individuals with respect to their bicycle use. A retrospective survey was conducted among 448 daily commuters with a stratified sampling method. Stratification was based on current behaviour and related to the stages: prepared for action, action, maintenance and relapse. The study reveals that the majority of people start to cycle around primary school age. At that age cycling provides prestige and is considered to be fun, and it is more attractive than walking when covering larger distances. No differences in this respect are found between people living in the city at that time and those in the rural areas, although in the latter case trip purposes for bicycle use show differences. Analysis of people in the relapse stage, i.e. when they have stopped cycling, indicates that transitions into the relapse stage occur from all other stages considered. In a considerable number of cases stopping to cycle coincides with an event in the life of the individual, e.g. leaving school, moving to the city, broken or stolen bicycle, involved in traffic accident, got married. A variety of reasons is reported as motivation to stop cycling, of which lack of (perceived) traffic safety is dominant. Moreover, cycling experiences a strong competition from the dala dala, the local minibus shared taxis.

Keywords: travel behaviour, bicycle commuting, transitions, stages of change, life cycle events.
\end{abstract}




\section{Introduction}

The recognition that transport systems need to become more sustainable is growing worldwide. In developing countries, high economic growth goes hand in hand with fast motorisation. It elicits the potential conflict between striving after more sustainable transport and the ambition to improve the standard of living of people. In policy discussions on sustainable transport non-motorized transport is gaining importance [1]. The majority of Africans travel on foot, or to a lesser extent, by bicycle. Cycling levels in urban areas, however, are generally lower than one might expect. In Dar-es-Salaam, it is estimated that only 5\% of the trips are made by bicycle [2]. Nevertheless, the future potential of cycling should not be underestimated: i) African cities are expanding fast and will continue to do so, making distances larger and unsuitable for walking; ii) good quality cycling infrastructure and facilities can contribute to reduction of poverty, particularly in the African context where access to jobs and services is poor because of long travel times, discomfort and unsafe conditions; iii) in cities cycling can provide a substantial contribution to the reduction of greenhouse gases in urban transport [3].

Although the city of Dar-es-Salaam has initiated programs [4] to increase the availability and use of low cost mobility such as BRT [5], there is a lack of detailed knowledge about and understanding of current travel behaviour, and more specific the identification of groups of people that are transport policy responsive and might consider shifts in modes of travel, i.e. use a bicycle. In earlier work $[6,7]$, the authors applied a market segmentation method that was based on a behavioural approach. In this approach, intentions to behaviour and actual behaviour are considered to be stages in a process. These stages were identified as market segments, and revealed to have different attitudes towards policy related interventions. The current paper presents the results of a retrospective study about the occurrence of transitions in behaviour (from one stage to another) and addresses the questions when these transitions take place in the life cycle of an individual, under what circumstances and why.

\section{Conceptual model}

The conceptual model in this study is derived from the theory of behavioural change and builds upon the transtheoretical model of Prochaska and Diclemente [8] and Prochaska and Velicer [9]. This stages of change model posits that behavioural change is a transition through a time-ordered sequence of stages reflecting the cognitive and motivational difficulties people encounter in implementing a general behaviour change goal into concrete actions. The basic elements of the model are both motivational (dealing with intention building, decision making and attitudinal readiness) and behavioural (the adoption process from stages of increased motivation, through tentative performance to regular practice of the behaviour).

The model has been developed and is widely used in health behaviour and health promotion research with a focus on physical activities [10-12]. From this 
perspective, a link with cycling behaviour, or in a broader sense travel behaviour, is easily made. However, still few studies [13, 14] have adopted the stages of change model for identifying and targeting pliable groups for travel behaviour change strategies. Previously, Nkurunziza et al. applied the stages of change model to bicycle commuters in Dar-es-Salaam to investigate its potential for market segmentation [6], and to study the different motivators and barriers for cycling for each of the segments [7]. As has been done in other studies, they slightly modified the operationalization of the stages of change model, and employed a different number of stages by adding a sixth stage (table 1).

\section{Table 1: $\quad$ Stages of change.}

\begin{tabular}{|c|c|c|}
\hline Stage & $\begin{array}{l}\text { Characterization } \\
\text { Prochaska et al. }[8,9]\end{array}$ & $\begin{array}{l}\text { Operationalization (w.r.t. daily activity) } \\
\text { Nkurunziza et al. [6, 7] }\end{array}$ \\
\hline Pre-contemplation & No intention to change & I never really think about or consider cycling \\
\hline Contemplation & Thinking about change & $\begin{array}{l}\text { I have never used a bicycle but sometimes } \\
\text { think about cycling }\end{array}$ \\
\hline Prepared for Action & Intention to change shortly & $\begin{array}{l}\text { I rarely or sometimes cycle but seriously } \\
\text { consider riding a bicycle }\end{array}$ \\
\hline Action & Action being taken & I cycle fairly often \\
\hline Maintenance & Has maintained action & I cycle regularly and almost everyday \\
\hline Relapse & - & I no longer cycle \\
\hline
\end{tabular}

Nkurunziza et al. [6] demonstrated the usefulness of the stages of change model in identifying homogeneous market segments in cycling attitudes and behaviour. The analysis revealed that neither cyclist segments nor non-cyclist segments in the stages of change process are the same, which has important implications for targeting cycling policies and promotional strategies. Their research also reveals that the effect of various motivators, barriers and policy interventions (i.e. personal, social and physical-environmental factors) varies among people in the different stages of cycling behaviour [7].

This paper presents the results of a second survey where opposed to earlier work the focus is on transitions in the stages of change model, in particular the ones between cycling segments. In a retrospective study transitions between stages are investigated in coherence with events and stages in the life cycle of individuals.

\section{Data collection}

The study was aimed at commuters who travel to main daily activities regularly and who currently use or have used the bicycle in the past for at least some or all of their trips. Main daily activities in this study are government/private office, personal commercial business and school/university. The restriction on commuters with bicycle experience implies that the study is constrained to the stages prepared for action, action, maintenance and relapse in the stages of change model. Based on local knowledge and earlier experiences [6, 7] the survey was conducted in pre-defined residential zones located along four major trunk roads in the city i.e. Morogoro, Bagamoyo, Nyerere and Kilwa Road. 
In November and December 2010, data was collected through a questionnaire, where respondents were approached with face-to-face personal interviews in the evenings, i.e. between 14.00 and 19.00 hours, to meet commuters back home as official working time ends at 15.00 hours. The interview technique was used because of the length and complex nature of the questionnaire, which had separate sections after the initial phase in which the main purpose was to classify the respondent in a particular stage of change enabling appropriate subsequent questions about travel behaviour in the past. This approach is efficient, enables clarification of questions when needed, and reduces response errors.

The objective of the survey was to sample an adequate number of people in each of the four stages considered, and to collect data on current travel behaviour as well as (motivations for) changes in behaviour in the past on the one hand, and data on events and changes in the life cycle of respondents on the other. Data items in the latter category include year and location of changes in residence, school, jobs/work and marital status. Thereby, the survey has a retrospective nature and the sampling technique is stratified, where the strata correspond to the four stages of change. The targeted sample size for the stratum relapse was set $50 \%$ larger than for the other strata, because of the specific interest in why, when and where people quit using the bicycle.

\section{Survey statistics}

Table 2 presents the main statistics of the survey. Within the time and budget constraints 448 well completed questionnaires were collected, of which some 100 for the stages prepared for action, action and maintenance each, and a little less than 150 for the stage relapse. Analogously to earlier experiences [6], sufficient sample sizes for the stages prepared for action and action were the hardest to get. The unequal gender distribution in the sampled population is caused by three factors: i) most females in Dar-es-Salaam are not engaged in daily commuting activities, ii) less females in Dar-es-Salaam use a bicycle, and iii) some females were part of the non-response group, because they were afraid to provide information without permission of their partner.

Table 2: $\quad$ Sample distribution by segment, gender and place of birth.

\begin{tabular}{lcccc}
\hline Stage of change & Males & Females & Total & \% born in Dar \\
\cline { 2 - 5 } \multicolumn{1}{c}{ segment } & $\mathrm{N}=390$ & $\mathrm{~N}=58$ & $\mathrm{~N}=448$ & 42 \\
\hline Prepared for action & 89 & 16 & 105 & 45 \\
Action & 87 & 13 & 100 & 54 \\
Maintenance & 92 & 6 & 98 & 43 \\
Relapse & 122 & 23 & 145 & 32 \\
\hline
\end{tabular}

A striking feature in the sample population is that the majority of respondents (58\%) was born outside Dar-es-Salaam. It shows, as in most developing countries, the strong influx of migrants from rural areas into cities. Dar-esSalaam is one of the fastest growing cities on the African continent with an 
average annual growth rate of $4.67 \%$ over the period $1990-2010$, and an estimated population of more than 3.3 million inhabitants in the year 2010 [15]. The vast majority of respondents born elsewhere moved to Dar-es-Salaam in their twenties.

The age of respondents varied between 15 and 70 years, but most of them (73\%) were aged between 20 and 40 years. The average age of the sample population, 30.6 years, was identical to an earlier survey [6], although there were tiny differences between the segments: prepared for action (30.8), action (28.8), maintenance (27.8) and relapse (33.7). In the sample population $48 \%$ of the respondents were married (46\% of the males, $62 \%$ of the females).

Table 3 indicates that there is a correlation between bicycle use and the type of daily activity. Private commercial business is dominant in both the action and maintenance segment. This is not surprising since a lot of people in Dar-esSalaam, alongside their formal work, earn their daily living from informal small business for which they often use a bicycle. On the other hand, office work whether private or governmental - is represented considerably in the stages prepared for action and relapse. The representation in the relapse stage suggests a link between bicycle use and status/income, since as a rule office work pays better. The modest share of students in the sample is influenced by the survey design, allowing only respondents of 15 years and older.

Table 3: $\quad$ Sample distribution by daily commuting activity and segment.

\begin{tabular}{lcccc}
\hline Daily commuting & Prepared for action & Action & Maintenance & Relapse \\
\cline { 2 - 5 } \multicolumn{1}{c}{ activity } & $\mathrm{N}=105$ & $\mathrm{~N}=99$ & $\mathrm{~N}=95$ & $\mathrm{~N}=144$ \\
\hline School/university & $18 \%$ & $18 \%$ & $14 \%$ & $8 \%$ \\
Office work & $50 \%$ & $31 \%$ & $25 \%$ & $66 \%$ \\
Private commercial business & $32 \%$ & $51 \%$ & $61 \%$ & $26 \%$ \\
\hline
\end{tabular}

\section{Results}

In a retrospective survey - in the context of an African city - it is hard, if not impossible, to collect detailed, reliable and accurate data for all transitions in the stages of change model. Some of the transitions, e.g. between prepared for action and action, and between action and maintenance, are supposed to pass off gradually, and might be difficult to reconstruct by respondents. Two exceptions are prominent: the start of the bicycle career, and the (temporary) ending of it. All respondents have been asked a number of questions about the start of their bicycle career (e.g. timing, location, motivations, bicycle use). Respondents categorized in the relapse stage were also asked questions about timing, location and motivations when they stopped cycling, as well as their bicycle use just before the stopping moment. All these data are combined with the historical data of the respondents (schools, jobs, places of residence, year of marriage, etc.). 


\subsection{Start of the bicycle career}

Table 4 shows, as expected, that most people start to cycle at a very young age and many before, at the start or during primary school. In this respect no differences are found between males and females in the sample. Table 5 shows the main drivers for adopting the bicycle as a mode of transport. Respondents were allowed to mention multiple motivations. The results indicate that at those ages social norms ('seeing others cycling') and peer pressure play an important role to start cycling. It provides young bicyclists prestige and cycling is considered to be fun. For young people the bicycle has a positive image: it is a step forward in their mobility career, in which previously walking was the main mode of transport. Bicycle availability at home stimulates cycling at earlier ages, and in quite a number of cases the purchase of a bicycle by parents was decisive. Convenience of the bicycle is another important driver: for travel over larger distances it saves considerable time, the bicycle is suitable as a means of transport to carry goods, and it is often the only affordable alternative mode for walking. Other reasons were mainly health and sports related.

Table 4: $\quad$ Age and life cycle stage at the start of the bicycle career.

\begin{tabular}{lclc}
\hline Age & $\mathrm{N}=440$ & Life cycle stage & $\mathrm{N}=440$ \\
\hline $0-9$ years & $33 \%$ & before primary school & $17 \%$ \\
$10-14$ years & $47 \%$ & at start primary school & $22 \%$ \\
$15-19$ years & $14 \%$ & during primary school & $44 \%$ \\
$20-24$ years & $4 \%$ & later in school career & $7 \%$ \\
25 years and older & $2 \%$ & during work career & $10 \%$ \\
\hline
\end{tabular}

Table 5: $\quad$ Categories of drivers for adopting the bicycle.

\begin{tabular}{lc}
\hline Drivers for adopting the bicycle & Sample \\
& $\mathrm{N}=448$ \\
\hline Conforming behaviour / peer pressure & 266 \\
Prestige and fun & 126 \\
Convenience / travel distances & 117 \\
Bicycle availability at home & 94 \\
Lack of alternative travel mode options & 60 \\
Means of transport & 56 \\
Other reasons & 20 \\
\hline
\end{tabular}

The dominant trip purpose of initial bicycle use (table 6) is social and recreational activities: visiting relatives and friends, and sports/playing activities. For home related activities, e.g. fetching water and firewood or going to the farmland, the bicycle is also popular, in particular in rural areas where the supporting role of young family members is strong and distances are substantial. Some $27 \%$ of the young cyclists use the bicycle to go to school (primary, secondary, college or university); although bicycle use for school trips in rural areas is somewhat higher, the difference is not notable.

For the small proportion of respondents, for whom the starting moment of cycling falls outside the education period or before and coincides with their working phase (table 4), the following characteristics apply: at that stage they are 
predominantly between 15 and 25 years old, have no or only primary education, earn a living in personal commercial business, and use the bicycle to carry goods over larger distances. They live more in the city than outside.

Table 6: Trip purposes of initial bicycle use, broken down by place of residence.

\begin{tabular}{lccc}
\hline Trip purpose & Total sample & $\begin{array}{c}\text { Living in } \\
\text { Dar-es-Salaam }\end{array}$ & $\begin{array}{c}\text { Living outside } \\
\text { Dar-es-Salaam }\end{array}$ \\
\cline { 2 - 4 } & $\mathrm{N}=446$ & $\mathrm{~N}=219$ & $\mathrm{~N}=227$ \\
\hline Social/recreational & $71 \%$ & $81 \%$ & $62 \%$ \\
Home related activities & $48 \%$ & $25 \%$ & $70 \%$ \\
School & $27 \%$ & $24 \%$ & $30 \%$ \\
Business/work & $13 \%$ & $17 \%$ & $10 \%$ \\
Market/shopping & $7 \%$ & $7 \%$ & $7 \%$ \\
\hline
\end{tabular}

Analysing the data in more detail by market segment, i.e. stage of change, reveals that no significant differences can be found with respect to timing, conditions, drivers and trip purposes of initial bicycle use. Therefore, the circumstances under which bicycle use has started, has no demonstrable correlation with cycling behaviour in a later stage, at least with respect to the categorisation in behavioural stages of change as applied in this study.

\subsection{Stopping with cycling}

Historical data of respondents in the relapse stage, i.e. people who have cycled before but do not cycle anymore, provides information about the decision to stop the use of the bicycle.

Table 7: $\quad$ Relapse stage sample by previous stage and length of cycling period.

\begin{tabular}{lcccc}
\hline Previous stage & \multicolumn{3}{c}{ Cycling period } & Sample \\
\cline { 2 - 4 } & One year or less & From 1 to 5 years & More than 5 years & N=145 \\
\hline Prepared for action & 3 & 8 & 33 & 44 \\
Action & 2 & 9 & 16 & 27 \\
Maintenance & - & 15 & 59 & 74 \\
\hline Total & 5 & 32 & 108 & 145 \\
\hline
\end{tabular}

Table 7 shows that transitions occur from all other stages considered: it suggests that the stages of change model the way it is applied in this study does not follow a time-ordered sequence of stages, but that cyclists in both the prepared for action, the action and the maintenance stage can make a direct transition into the relapse stage. It occurs most often from the maintenance stage (51\%), followed by the prepared for action stage (30\%). The table also shows that most people (74\%) have cycled for a considerable time period, i.e. more than 5 years. From a marketing and transport policy perspective, it is worth mentioning that the people who have cycled on an everyday basis (i.e. the maintenance segment) for at least 5 years or more constitute the largest subgroup of the relapse segment. 
The average age at which people from the relapse segment end their cycling career is 23.0 years after an average cycling period of 11.4 years. In the survey respondents were interviewed extensively about timing and motivations for stopping. These data were compared, checked and analysed with the historical data collected in another part of the questionnaire dealing with retrieving main events in the life cycle of the individual. The objective of this analysis was to investigate whether a behavioural change in bicycle use, i.e. in this case ending to cycle, coincides with events in a person's life.

Table 8: $\quad$ Mapping the end of the cycling career upon (timing of) events.

\begin{tabular}{|c|c|c|c|}
\hline $\begin{array}{l}\text { End time of } \\
\text { cycling career }\end{array}$ & & $\begin{array}{l}\text { Sample } \\
\mathrm{N}=145\end{array}$ & \\
\hline No event detected & & 53 & \\
\hline Coincides with event & & 92 & \\
\hline of which & $\begin{array}{l}\text { moving to the city } \\
\text { start/change of work/job } \\
\text { end/change of school } \\
\text { involved in road accident } \\
\text { got married } \\
\text { moving within the city }\end{array}$ & & $\begin{array}{c}38 \\
31 \\
29 \\
16 \\
10 \\
5\end{array}$ \\
\hline
\end{tabular}

Remarkably, in $63 \%$ of the cases a direct relationship could be found with an event in a person's life (table 8). This result indicates that people often reconsider their travel mode choice at time instants when major changes take place in location and/or nature of daily activities, or due to personal conditions/experiences. From a transport policy perspective this is an important finding. Moving to the city Dar-es-Salaam appears to be a reason to stop cycling. This event often coincides with a change in school (college or university) or a change in work/job. Many factors can explain this behaviour: i) people do not take their bicycle along when moving, ii) people settle in neighbourhoods far from the main activity centres, iii) the city offers affordable alternative travel modes, and iv) cycling infrastructure is absent or has poor quality, and therefore cycling is perceived as very unsafe. These explanations are confirmed by the answers of respondents to the question which factors contributed to quit cycling: no bicycle available anymore (28 times), travel distances too far and thereby too time consuming (21), other transport options e.g. the local minibus shared taxis, dala dala (18), lack of adequate bicycle infrastructure (30) and fear for road accidents (75). The (perceived) lack of traffic safety for cyclists in Dar-esSalaam appears to be alarming: this finding is affirmed by the substantial number of people that stopped cycling immediately after they or their relatives were involved in a road accident on a bicycle (table 8).

There are also social and cultural factors involved in why people stop cycling. After a certain juvenile age, the originally positive image of the bicycle (at the start of the cycling career) changes dramatically, and the bicycle gets associated with a poor man's mode of transport. Answers in the survey like "feel ashamed to ride a bicycle" and "fellow students laughed at me when riding a bicycle" are manifestations of this huge change of image. As soon as people envisage a 
higher status in the future and can afford other modes of transport, they quit cycling and fully neglect potential advantages of bicycle use (e.g. avoiding traffic jams, flexibility, pollution reduction, health issue). This behaviour reinforces the negative image of the bicycle. Currently, low income people doing private informal business is the dominant group in the maintenance segment [6]. If one is interested in promoting bicycle use, one has to break this vicious circle.

Although the number of females in the sample is rather low, it should be noted that a number of them explicitly stated that they had to stop after marriage or after giving birth to a child, because their husband did not give permission to continue to cycle. Females also said to stop because they were afraid of losing their virginity. It shows that there are still many fallacies on this subject.

Another group of people (some 16\%) stop cycling as soon as they own a car or a motor-cycle. Although the purchase of a car or motor-cycle could also be considered as an event in a person's life, this group belongs to the category 'no event detected' in table 8. The group is rather homogeneous and consists of males aged between 25 and 50, who do office work (private or governmental), belong to the highest income class, and use their vehicle on a daily basis to their work.

The final subgroup in the relapse stage (some 20\%) decided to stop cycling based on an appraisal of attributes of the bicycle system (e.g. costs, time, comfort, safety) in comparison with alternative modes of transport. According to the information contained in the survey, their decision cannot be related to any specific event. Factors mentioned are: purchase costs of a bicycle, travel time by bicycle, weather conditions, physical effort, and lack of road safety. The majority of these people use dala dala for the travel to their daily activity. Others use private motorized transport (car/motor-cycle owners) or walking (shorter distances).

\subsection{Other findings}

As has been mentioned earlier, other transitions between stages are hard to catch in a retrospective survey in the African context, because they usually take place gradually and more slowly. However, respondents in the prepared for action, action and maintenance stage were asked whether they have stopped cycling temporarily in the past. A small minority (less than 10\%) confirmed that they did. Causal factors mentioned are: attending boarding school, health issues and loss of the bicycle (stolen or broken). Time periods in which they did not ride a bicycle vary from a few months till 4 to 5 years.

In section 5.2 it was shown that a large proportion of people in the relapse stage stopped with cycling when moving from the country to the city. In this respect it is interesting to look also at the people, that started cycling before coming to Dar-es-Salaam, and that continued to cycle after arriving in the city. The data base does not allow us to calculate the percentage of people that falls into this category because of the stratified sampling method. However, analysis of the data per stratum reveals that it concerns $51 \%$ of the prepared for action, $40 \%$ of the action and $49 \%$ of the maintenance segment. At the time of the survey they were on average for a period of 9.6 years living in Dar-es-Salaam 
and still cycling. These findings indicate that also a substantial part of the population that migrated to the city continues to ride a bicycle for a considerable period of time as well. Therefore, one needs to be careful in drawing conclusions: moving to Dar-es-Salaam does not necessarily imply that people quit cycling, but for a number of people the decision to quit cycling coincides with their move to the city.

\section{Conclusions}

Cycling has a huge potential in African cities: it provides better access to activities and facilities, creates more employment opportunities and enhances the maintenance of social networks and community cohesion [16]. For most Tanzanians bicycles are relatively inexpensive and affordable compared to other travel modes [1]. Many Tanzanians are introduced to cycling when they are young, both in rural areas and in cities. This study shows that at that age the bicycle is supportive and attractive in saving time in home and school related activities. Dar-es-Salaam is the commercial centre of Tanzania and a hub that connects the country to the rest of the world. Its employment opportunities attract many people to migrate to the city, and the city grows fast in population size and in area. The main structure of the city road network consists of four major arterials radiating from the city centre areas Kariakoo and Kivikuni to the north, north-west, west and south, complemented with a dense road network in urban areas. Most roads do not have footways or separate lanes for bicycle traffic, and many roads have poor surface conditions. Existing bicycle lanes, where they exist, fail to ensure connectivity and access to popular destinations.

The absence of basic requirements for a fit-for-purpose bicycle network and the lack of road safety, together with a poor government transport policy regarding non-motorized transport [4], explain why many people in the city quit cycling and why only a low percentage of trips in Dar-es-Salaam is made by bicycle. People migrating to the city often decide not to use the bicycle anymore as soon as they arrive in the city, and also many residents take that step and change their travel mode in due time, often simultaneously with a change in school, work or place of residence. As a consequence, these decisions generate a loss in mass and variety of bicycle use, make the bicycle appearance even more rare and thereby more dangerous, and strengthen the image that cycling is for captive users with low incomes.

A remarkable finding is that the originally positive image that young people attribute to the use of the bicycle (prestige, fun, convenience) changes completely and to the worse within a number of years. At the time they leave school, they feel ashamed to ride a bicycle. Social norms and peer pressure play an important role in this respect. It suggests that promotional campaigns to promote cycling should include educational programmes for primary and secondary schools focussing on cycling-inclusive transport and the aspects of sustainability, liveability and health. Such campaigns could be made even more effective by the supply of a larger variety of fancy (and more expensive) 
bicycles, since status appears to be important and new generations are sensitive for making steps in their mobility pattern and behaviour.

Behavioural changes with respect to using the bicycle appear to occur when activity locations of people change: school/college/university, business/office and home. Then travel modes are reconsidered, and in many cases the dala dala seems to be a tough competitor with the bicycle. It implies that integrated spatial and transport policies need to be developed where planning of bicycle networks and parking facilities is integrated with spatial planning of main activity centres. Taxing and financing schemes that relieve and/or spread out the costs of purchase of a bicycle could further strengthen the position of the bicycle in competition with other transport modes.

From a methodological perspective, it can be concluded that the stages of change model appears to be very useful. In this retrospective study with the objectives of detecting transitions in behaviour in bicycle use in the city of Dares-Salaam, investigating the coincidence with important events in the life cycle of individuals and deriving motivations for behavioural change, new insights have been gained that can be useful for transport policy development and planning with a focus on promoting bicycle use. As such it adds to earlier experiences with behavioural market segmentations [6] and deriving segment- specific motivators and barriers for changing attitudes and behaviour of cycling [7].

\section{Acknowledgements}

This research is part of the Cycling Academic Network (CAN) and was funded by the Dutch Ministry of Development Cooperation through the Bicycle Partnership programme (BPP) of the Interface for Cycling Expertise (I-CE), and co-funded by the University of Twente, the Netherlands. The authors would like to acknowledge the support of the University of Cape Town, South Africa, and the field work assistance by the DART Agency, Dar-es-Salaam City Council, UWABA, and the Department of Transportation and Geo-technical Engineering, University of Dar-es-Salaam.

\section{References}

[1] Brussel, M.J.G. \& Zuidgeest, M.H.P., Cycling in developing countries: context, challenges and policy relevant research (Chapter 8). Cycling and Sustainability, ed. J. Parkin, Emerald Group Publishing Limited: Bingley, UK, pp. 181-216, 2012.

[2] I-CE, Cycling Planning and Promotion, Unpublished report, Interface for Cycling Expertise, Utrecht, The Netherlands, 2007.

[3] Massink, R., Zuidgeest, M.H.P., Rijnsburger, J., Sarmiento, O.L. \& Van Maarseveen, M.F.A.M., The climate value of cycling, Natural Resources Forum, 35(2), pp. 100-111, 2011.

[4] JICA, Dar-es-Salaam Transport Policy and System Development Master Plan, Final Report, Dar-es-Salaam City Council, Dar-es-Salaam, 2008. 
[5] Nkurunziza, A., Zuidgeest, M., Brussel, M. \& Van den Bosch, F., Spatial variation of transit service quality preferences in Dar-es-Salaam, Journal of Transport Geography, 24, pp. 12-21, 2012.

[6] Nkurunziza, A., Zuidgeest, M. \& Van Maarseveen, M., Identifying potential cycling market segments in Dar-es-Salaam, Tanzania, Habitat International, 36, pp. 78-84, 2012.

[7] Nkurunziza, A., Zuidgeest, M., Brussel, M. \& Van Maarseveen, M., Examining the potential for modal change: Motivators and barriers for bicycle commuting in Dar-es-Salaam, Transport Policy, 24, pp.249-259, 2012.

[8] Prochaska, J.O. \& Diclemente, C.C., The Transtheoretical Approach: Crossing Traditional Boundaries of Therapy, Dow Jones-Irwin, Illinois, USA, 1984.

[9] Prochaska, J.O. \& Velicer, F.W., The transtheoretical model of health behaviour change, American Journal of Health Promotion, 12, pp. 38-48, 1997.

[10] Marttila, J., Laitakari, J., Nupponen, R., Miilunpalo, S. \& Paronen, O., The versatile nature of physical activity - on the psychological, behavioural and contextual characteristics of health-related physical activity, Patient Education and Counseling, 33, pp. 29-38, 1998.

[11] Miilunpalo, S., Nupponen, R., Laitakari, J., Marttila, J. \& Paronen, O., Stages of change in two modes of health-enhancing physical activity: methodological aspects and promotional implications, Health Education Research: Theory and Practice, 15, pp. 435-448, 2000.

[12] Kloek, G.C., Van Lenthe, F.J., Van Nierop, P.W.M., Schrijvers, C.T.M. \& Mackenbach, J.P., Stages of change for moderate-intensity physical activity in deprived neighborhoods, Preventive Medicine, 43, pp. 325-331, 2006.

[13] Gatersleben, B. \& Appleton, M.K., Contemplating cycling to work: attitudes and perceptions in different stages of change, Transportation Research Part A: Policy and Practice, 41(4), pp. 302-312, 2007.

[14] Rose, G. \& Marfurt, H., Travel behaviour change impacts of a major ride to work day event, Transportation Research Part A: Policy and Practice, 41(4), pp. 351-364, 2007.

[15] UN-HABITAT, The State of the World's Cities 2012/2013: Prosperity of Cities, UN-HABITAT, Nairobi, Kenya, 2012.

[16] Bryceson, D., Mbara, T.C. \& Maunder, D., Livelihoods, daily mobility and poverty in Sub-Saharan Africa, Transport Reviews, 23(2), pp 177-196, 2003. 